\title{
New Developments and Applications in Quantitative Electron Spectroscopic Imaging of Iron in Human Liver Biopsies
}

\author{
A. L. D. BECKERS,$\S \S$ W. C. DE BRUIJN, $\uparrow$ M. I. CLETON-SOETEMAN, $\$$ H. G. VAN EIJK, $\ddagger$ and \\ E. S. GELSEMA*
}

\author{
*Department of Medical Informatics, P.O. Box 1738, 3000 DR, Rotterdam. The Netherlands \\ $\dagger$ AEM Unit, Clinical Pathology Institute, P.O. Box 1738, 3000 DR, Rotterdam. The Netherlands \\ $\ddagger$ Department of Chemical Pathology. Erasmus University Rotterdam, P.O. Box 1738, 3000 DR. Rotterdam. The Netherlands
}

(Received 27 March 1997; accepted 30 May 1997)

\begin{abstract}
Reliable iron concentration data can be obtained by quantitative analyses of image sequences, acquired by electron spectroscopic imaging. A number of requirements are formulated for the successful application of this recently developed in situ quantitative type of analysis. A demonstration of the procedures is given. By application of the technique it is established that there are no significant differences in the average iron loading of structures analysed in liver parenchymal cells of a patient with an iron storage disease, before and after phlebotomy. This supports the hypothesis that the process of iron unloading is an organelle specific process. Measurement of the binary morphology, represented by the area and contour ratio of the iron containing objects revealed no information about differences between the objects. This finding contradicts the visual suggestion that ferritin clusters are more irregularly shaped than the other iron objects. Also, no differences could be found in this sense between the situations before and after phlebotomy. With respect to the density appearance, objects that have an inhomogeneous iron loading averagely contain more iron. This observation does correspond well with the visual impression of the increasingly irregular appearance of more well-loaded structures. 1997 Elsevier Science Ltd. All rights reserved
\end{abstract}

Key words: energy-filtered transmission electron microscopy (EFTEM), electron energy-loss spectroscopy (EELS), electron spectroscopic imaging (ESI), image processing, iron, ferritin, haemochromatosis, human liver, phlebotomy.

\section{INTRODUCTION}

Element quantitation by electron spectroscopic imaging (ESI) in biological tissues is, from several points of view, a rather complicated matter: electron scatter theory is complex and the element preservation in tissue sections has to be carefully considered. Also, the experimental conditions in which image sequences are to be acquired under stable instrumental conditions and processing with proper analytical (computer) techniques deserve special attention. These difficulties, in addition to the instrumental costs, make that quantitative studies are rare, especially in the bio-medical field. Over the last years we invested considerably in making ESI more accessible in this area.

A number of guidelines may be formulated which have to be considered in order to sensibly apply quantitative ESI:

(1) There must be some proof that element losses during the applied tissue processing techniques and during the measurements are minimized. Also, de-localization of element quantities should be minimal as result of the material preparations.

(2) To allow the use of relative simple expressions for quantification one has to verify that the sections are sufficiently thin. If the probability of multiple

§Corresponding author: TNO-FEL, group 3-4, P.O. Box 96864, 2509 JG The Hague. The Netherlands. E-mail: Beckers@fel.tno.nl inelastic interactions over the section thickness increases, straightforward application of the frequently published expressions becomes inaccurate and necessitates correction or spectral deconvolution. A basic requirement is the validation of used quantification expressions by measuring the degree of absence of multiple scattering.

(3) Distortions in the image formation process have to be known and for the crucial problems corrections should be at hand.

(4) Valid mathematical/statistical procedures have to be available that deal with the background problem which is fundamental to electron energy-loss spectroscopy (Unser et al., 1987; Beckers et al., 1993).

(5) For the local measurement of element concentrations statistically sound detection procedures have to applied (Van Puymbroeck et al., 1992). Not only the presence of element quantities has to be demonstrated, but also the absence of detections in situations where no element under investigation is present. Bonnet et al. (1988) showed the power of creating 'ghost'-images under such conditions, without the need of additional image acquisition.

Our present contribution, which is a summary of our procedures for chemical element quantitation in ultrathin sections and the application of this technique to liver analysis, includes all five aspects. It has been performed on a Zeiss EM 902 (Zeiss, Oberkochen 


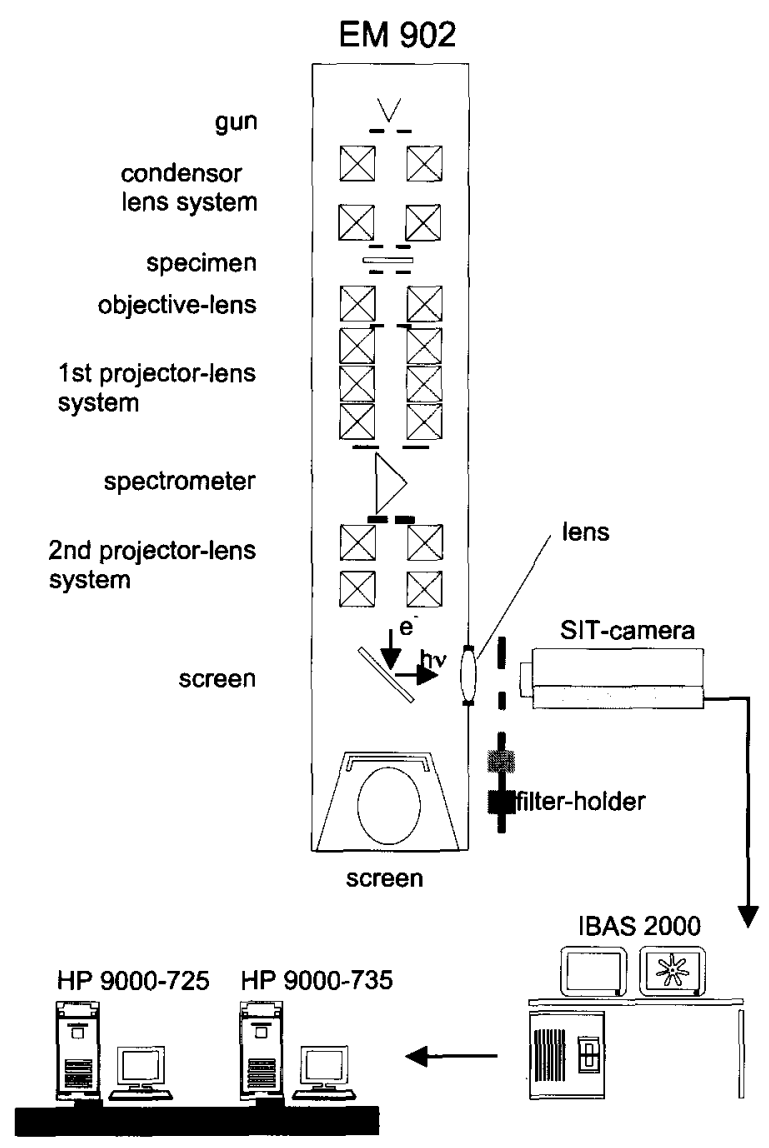

Fig. 1. An overview of the laboratory equipment used for electron microscopic imaging and quantitative analysis.

Germany) with an in-column spectrometer (Fig. 1). The instrument is, however, adapted (Fig. 1) for quantitative measurements by the introduction of calibrated Kodak No 96 neutral density filters, ranging from $\mathrm{D}=0$ (no filter) to $\mathrm{D}=6$, in the optical path towards the TV camera (Bosch TYC 9A SIT, or a SIT-66 from Dage-MTI Inc.). This adaptation allows one to acquire the low intensity element-related images at the same camera settings as the high-intensity images in the zeroand low-loss region and to use the $\mathrm{D}$ values of the filters for the calibration of the images. For details, see de Bruijn et al. (1993); Beckers et al. (1994) and also Sorber et al. (1990) and Reimer (1991).

With respect to quantification a strategy has been proposed years ago to use bio-standards, embedded together in Epon with the tissues, for analysis by electron-probe X-ray microanalysis (EPMA). This procedure can also be applied for ESI, (de Bruijn and Cleton-Soeteman, 1985). Following this approach, the tissue processing procedure included co-embedding of element-loaded (e.g. iron) Chelex ${ }^{100}$ ion-exchange beads. This allows measurements of the unknown and standard shortly after each other in the same section, which contributes to the accuracy of measurement.

The biological aim to analyze the iron contents of human biopsy material by ESI is: (1) to answer questions about iron loading in patients suffering from haemochromatosis, an iron storage disease, (2) to know the iron concentrations in the various recognizable storage compartments in the liver parenchymal cells (ferritin particles, clusters, lysosomes and siderosomes) in situ and (3) to learn about the removal of iron from these compartments during the patient's phlebotomy treatment (controlled bleeding), which was known to reduce bio-chemically the mean iron tissue contents and to result in a numerical reduction of the iron-containing compartments in the liver parenchymal cells. The first two questions have been addressed before, (Cleton et al., 1986; Beckers et al., 1996). Here we will concentrate on the last question. The hypothesis tested is whether the unloading of iron from the cell is an organelle specific process. The other question addressed is to see if some proof for the frequently suggested relation between the degree of iron loading of objects (ferritin clusters, lysosomes, siderosomes) and the morphology of these objects can be found. Clusters, which are (visually) less heavily loaded are suggested to have a more irregular shape than the well-loaded lysosomes and siderosomes, because of the presumed absence of a membrane. Also, more heavily loaded structures seem to be more inhomogeneous in appearance.

\section{MATERIAL AND METHODS}

The material was obtained from an iron-overloaded male patient, 37 years of age. Clinically, the patient was diagnosed to have an idiopathic haemochromatosis. Percutaneous liver needle biopsy specimens were obtained before and after phlebotomy. The treatment consisted of 20 venesections by which a total amount of $3 \mathrm{~g}$ iron was removed from the body. Perls' blue staining of histological sections revealed a grade 4 overload according to Scheuer (1977) before phlebotomy and grade 1-2 after treatment. Several tissue blocks of $1-2 \mathrm{~mm}^{3}$ were glutaraldehyde fixed, post-fixed with $\mathrm{OsO}_{4}$ and embedded in Epon together with Fe-loaded Chelex ${ }^{100}$ (BioRad). Ultrathin sections of approximately $60-70 \mathrm{~nm}$ were subsequently cut and put on 200 mesh copper grids without a carrier film. Material of the patient before and after phlebotomy is referred to by A and B, respectively. Stearns et al. (1994) showed that the loss of iron during similar tissue processing procedures is minimal. We did not perform such an evaluation ourselves, because the amount of material was restricted.

Before acquisition of any iron related image sequence, the microscope is aligned and adjusted according to the instructions. In the illumination system (Fig. 1) a condenser diaphragm with a hole of $400 \mu \mathrm{m}$ is used. A $90 \mu \mathrm{m}$ diaphragm is inserted below the objective lens to obtain an aperture of $17 \mathrm{mrad}$. The slit in the spectrometer is adjusted to $20 \mathrm{eV}$ width and for offset calibration of the energy-loss scale, a negative bias of a few eV's is set as a guard region. The threshold energy for iron ( $\mathrm{Fe}$ ) $\mathrm{L}_{2,3}$-ionization is $708 \mathrm{eV}$ and particularly useful for ESI because of its marked edge in the energyloss spectrum. To investigate the amount of iron in parenchymal cells, ESI-sequences were obtained at $12000 \times$ magnification, which corresponds to a sample distance in the digital images of $5.5 \mathrm{~nm}$. The camera 
Table 1. Acquisition protocol for iron

\begin{tabular}{|c|c|c|c|}
\hline Image 1: $608 \mathrm{eV} / \mathrm{D}=0$ & Image 2: $608 \mathrm{eV} / \mathrm{D}=0$ & Image 3: $628 \mathrm{eV} / \mathrm{D}=0$ & Image 4: $648 \mathrm{eV} / \mathrm{D}=0$ \\
\hline Image 5: $668 \mathrm{eV} / \mathrm{D}=0$ & Image 6: $688 \mathrm{eV} / \mathrm{D}=0$ & Image 7: $708 \mathrm{eV} / \mathrm{D}=0$ & Image 8: $728 \mathrm{eV} / \mathrm{D}=0$ \\
\hline Image 9: $748 \mathrm{eV} / \mathrm{D}=0$ & Image $10: 608 \mathrm{eV} / \mathrm{D}=0$ & Image $11: 0 \mathrm{eV} / \mathrm{D}=4$ & Image $12: 20 \mathrm{eV} / \mathrm{D}=3$ \\
\hline Image $13: 40 \mathrm{eV} / \mathrm{D}=3$ & Image $14: 60 \mathrm{eV} / \mathrm{D}=3$ & Image $15: 80 \mathrm{eV} / \mathrm{D}=3$ & Image 16: Dark sensor \\
\hline Image 17: Dark sensor & $\begin{array}{l}\text { Image } 18: 0 \mathrm{eV} / \mathrm{D}=4 \\
\text { (no specimen) }\end{array}$ & $\begin{array}{l}\text { Image } 19: 0 \mathrm{eV} / \mathrm{D}=4.3 \\
\text { (no specimen) }\end{array}$ & $\begin{array}{l}\text { Image } 20: 250 \mathrm{eV} / \mathrm{D}=0 \\
\text { (new camera gain) }\end{array}$ \\
\hline
\end{tabular}

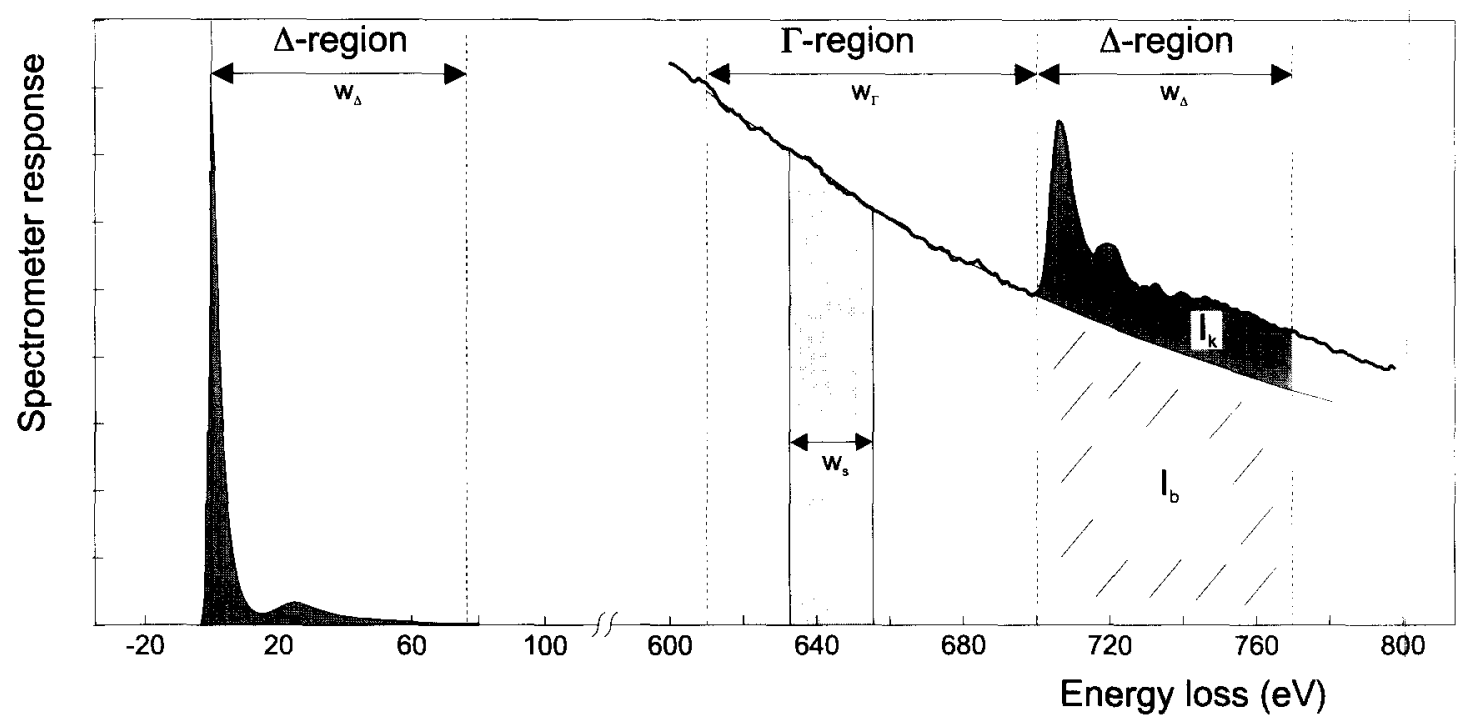

Fig. 2. The principle of model-based background correction and the relevant spectral regions are shown. The background $I_{b}$ is to be removed to obtain the net-image $I_{k}$ in the $\Delta$-region. The $\Gamma$-region is used for fitting the model. $W_{s}$ is width of the energy+selecting slit present in the energy-dispersive plane below the spectrometer.

used was the SIT-66. The regions of interest were selected by the criterion that several dense structures of considerable size had to be present within the image frame. For these objects, a maximum diversity in density and morphology was pursued. In a number of sections, five regions were addressed to acquire data sets of the situation before phlebotomy and similarly seven regions for the situation after phlebotomy. In each section, an ESI sequence of the Fe-Chelex was also acquired for calibration. Analog zero-loss energy-filtered transmission electron micrographs were obtained at $12000 \times$ magnification for visual inspection of all digitally acquired regions. A digital sequence of either a tissue or standard region consists of 20 images and is acquired under the spectral and filter density conditions as given in Table 1.

The processing of the data was carried out according to the analysis procedures outlined in Beckers et al. (1994, 1996). To make this contribution self explanatory, the procedures are summarized in short for iron in particular. The analysis of $\mathrm{Fe}$ is performed in a spectral region where the so-called 'power-law' model is valid for the a-specific spectral background (Colliex, 1985; Colliex et al., 1986; Egerton, 1986). Figure 2 illustrates the principle of model-based background correction and defines the relevant spectral regions and used terminology $\left(w_{\Gamma}=100 \mathrm{eV}, \mathrm{w}_{\Delta}=60 \mathrm{eV}, \mathrm{w}_{\mathrm{s}}=20 \mathrm{eV}\right)$. The background is removed by the procedure described in Beckers et al. (1993) by the statistical estimation of $I_{\mathrm{b}}$ from five pre-edge images, followed by the subtraction: $I_{\mathrm{k}}=I-I_{\mathrm{b}}$.
The expression for the iron concentration in terms of the number of atoms iron per unit volume can by approximation be given as (Egerton, 1986):

$$
N_{\mathrm{Fe}}=\frac{I_{\mathrm{k}}(\beta, \Delta)}{I_{\mathrm{T}}(\beta, \Delta) \cdot \sigma_{k}(\beta, \Delta) \cdot t}
$$

in which the intensity at the edge $I_{\mathrm{k}}$ is related to the total intensity $I_{\mathrm{T}}$ in the zero and low-loss region, both acquired at the same objective lens aperture $\beta$ and integrated over the same $\Delta$ region and $\sigma_{\mathrm{k}}(\beta, \Delta)$ is the partial cross-section. The section thickness is represented by $t$.

In the same ultrathin section the iron standard is present. Evaluating equation (1) in a such a region, a similar expression can be obtained for the iron quantity $\left(N_{\mathrm{Fe}, \mathrm{s}}\right)$ in the standard. When it is assumed that the partial cross-sections of iron in tissue and standard are about the same, and the ratio of $I_{\mathrm{k}}$ over $I_{\mathrm{T}}$ is replaced by $R_{\mathrm{Fe}}$ and $R_{\mathrm{Fe}, \mathrm{s}}$ for respectively the tissue and the standard, equation (1) converts into:

$$
N_{\mathrm{Fe}}=\frac{R_{\mathrm{Fe}}(k, \beta, \Delta)}{R_{\mathrm{Fe}, \mathrm{s}}(k, \beta, \Delta)} \cdot N_{\mathrm{Fe}, \mathrm{s}}
$$

For the presently used iron-loaded Chelex standard the concentration $\mathrm{N}_{\mathrm{Fe}, \mathrm{s}}=1.64$ atoms $\mathrm{Fe} / \mathrm{nm}^{3}$ has been calculated (Sorber et al., 1991). 


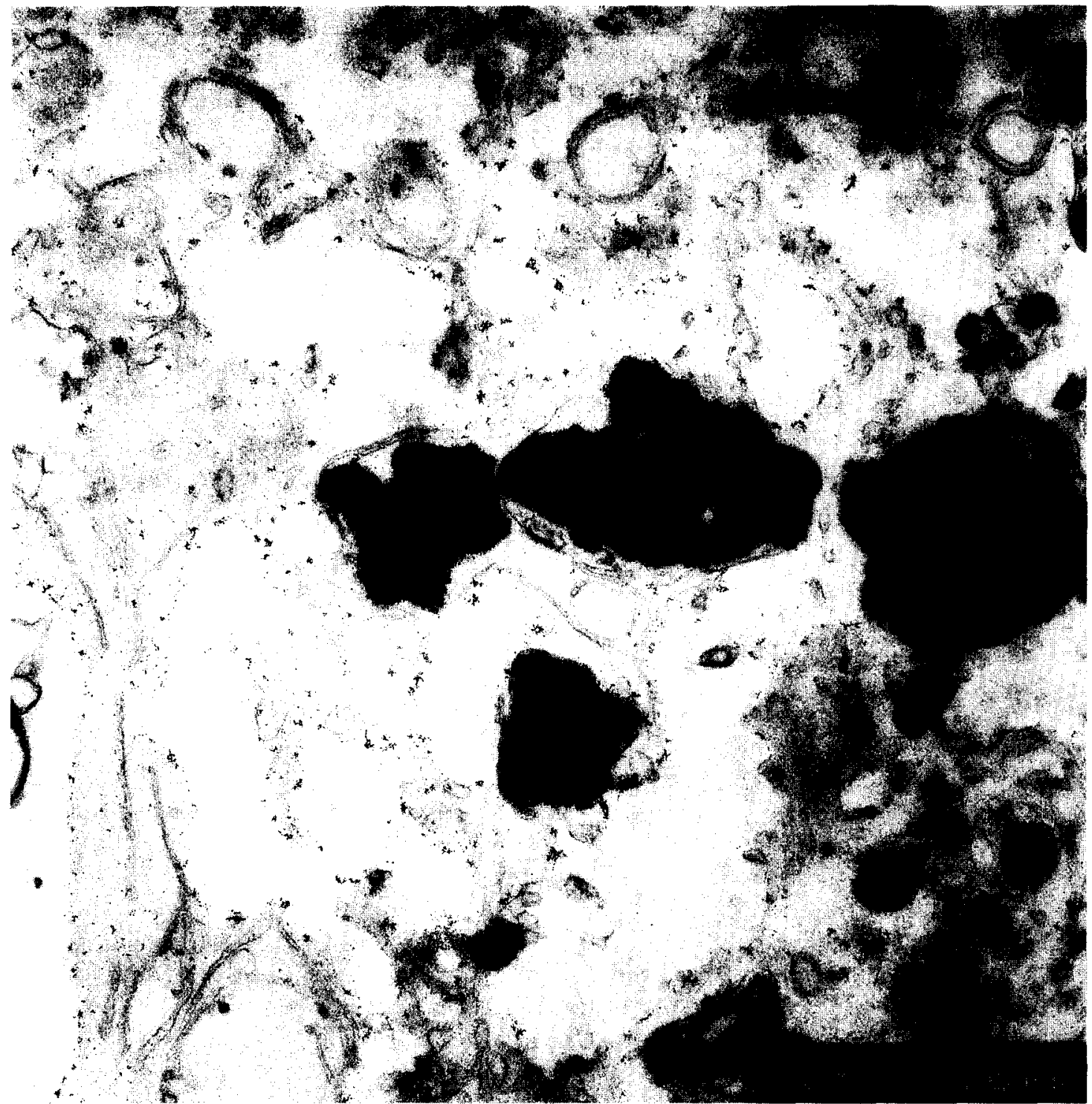

Fig. 3. Conventional electron micrograph of the analyzed field of interest in a liver parenchymal cell. In the cytoplasm the lysosomal and siderosomal structures have a dark granular appearance that is caused by the very dense particles resembling the $6 \mathrm{~nm}$ cores of ferritin molecules. Also visible are parts of the endoplasmatic reticulum and a large number of small ferritin clusters.

The quantification expression equation (2) can only be used in measurement areas where the specimen thickness is less than the plasmon mean free path $\left(\mathrm{t}<\lambda_{\mathrm{p}}\right)$ and $\Delta$ is sufficiently large to include a representative sample of the edge intensity. An estimation for the relative section thickness is obtained in the low-loss region of the spectrum (Egerton and Cheng, 1987):

$$
t / \lambda=\ln \frac{I_{t}\left(\beta, \Delta_{2}\right)}{I_{0}(\beta)}
$$

where $I_{t}\left(\beta, \Delta_{2}\right)$ is the total area under the spectrum truncated at an energy-loss range $\Delta_{2}(=100 \mathrm{eV})$ and $I_{0}(\beta)$ is the zero-loss intensity. Practically, the measurements in the low-loss region can be combined, since $I_{\mathrm{T}}$ and $I_{t}$ are evaluated in overlapping regions.

Referring to images in Table 1, Image 2-9 and Image 11-13 are directly used for concentration measurement in reference to a similar set of the standard. Image 11-15 are used for the section thickness assessment. The other images are exploited for specific corrections (camerarelated shading and non-linearity, specimen drift) and noise measurement for the calculation of signal to noise ratio (SNR-) images as described in Beckers et al. (1994, 1996). The validity of the image data was evaluated by the analysis of ghost images and checking for drift (which in principle was compensated) and radiation damage. A ghost image in this case is an image which is expected to contain no iron, because it is obtained from a spectral region before the iron edge.

The iron concentration distribution images generally showed clustered amounts of iron, such as ferritin clusters, lysosomes and siderosomes. These structures were considered as objects. The thresholding of the SNR-image of the net-intensity image formed the basis for object analysis. These images were thresholded at a level equivalent to 3.0. The result is a binary image, which represents all significant iron contributions in the imaged region. Because the quantity to be measured is 


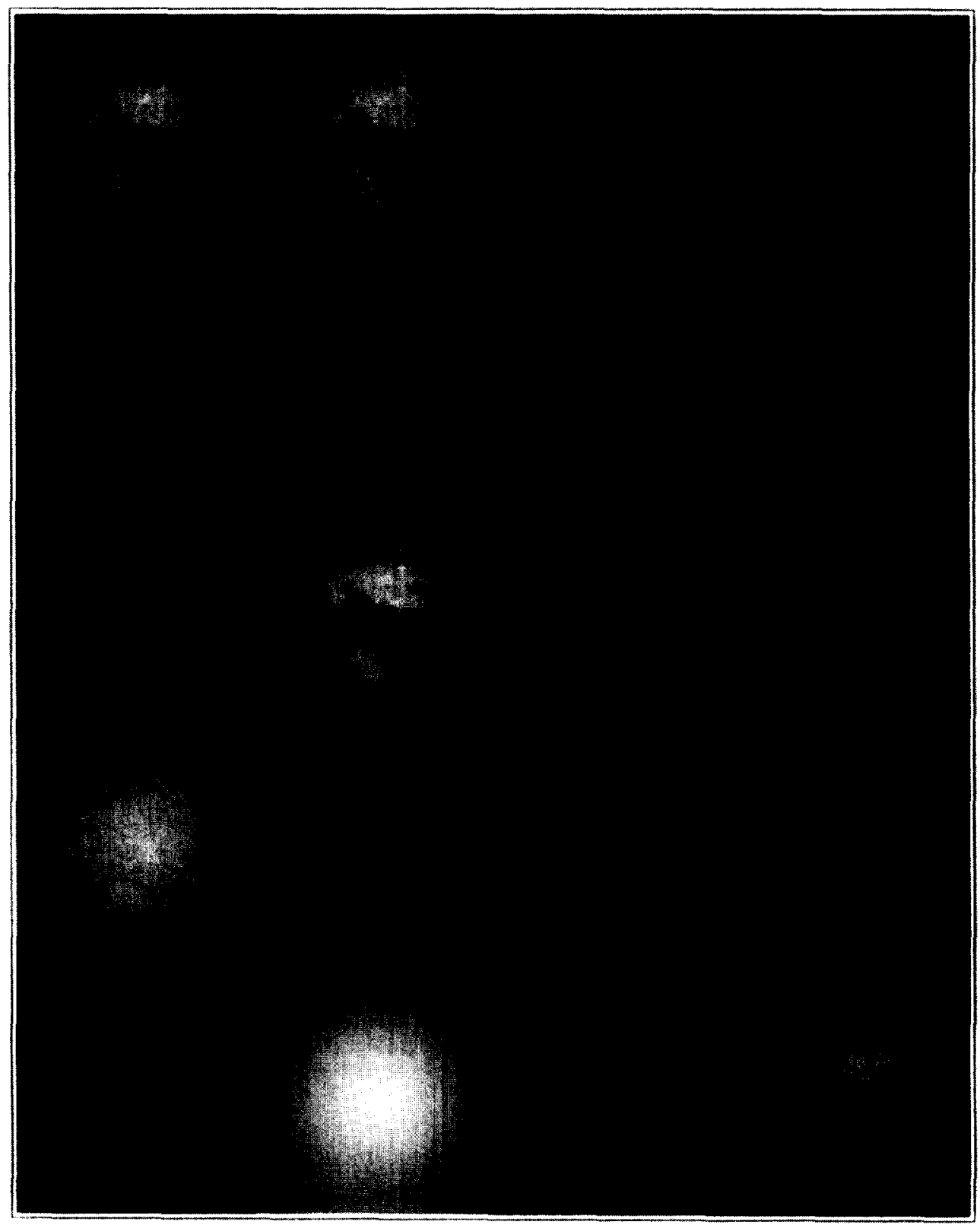

Fig. 4. A composition of all digital images acquired from the area in Fig. 3 with the protocol in Table 1.

the concentration, it is important that each object fills the section entirely (in the depth direction). Problems related to this cannot be entirely avoided, but small objects can at least be removed and the borders of the objects excluded from the analysis. Therefore, objects with a size smaller than $70 \mathrm{~nm}$, measured by the diameter of an inscribed disc, were removed. Also, the binary objects were eroded once with a $3 \times 3$ square structuring element to remove the borders. The binary mask that remained after these steps was used to identify the individual objects. A concentration histogram was made of each remaining object as a representation of the iron distribution.

To compare the effect of phlebotomy on the ironloading of the objects, the average concentration of each object $N_{\text {avg }}$ and the extreme values $N_{\min }$ and $N_{\max }$ were determined for situations $\mathrm{A}$ and $\mathrm{B}$. The Wilcoxon-test was performed to determine the effect of phlebotomy on the average object concentration.

Analysis of the shape of the objects was restricted to the measurement of the object area (A) and the contour ratio (CR). These features were only evaluated for those objects not connected to the image border. The object area is defined as the sum of all object pixels and the contour ratio is defined by:

$$
C R=\sqrt{\frac{\text { perimeter }^{2}}{4 \pi A}}
$$

Circular objects have a CR-value of 1 , for non-circular objects, $C R>1$. Both features were also studied in relation to the average object concentration ( $\left.N_{\text {avg }}\right)$. The inhomogeneity of the objects, represented by the 

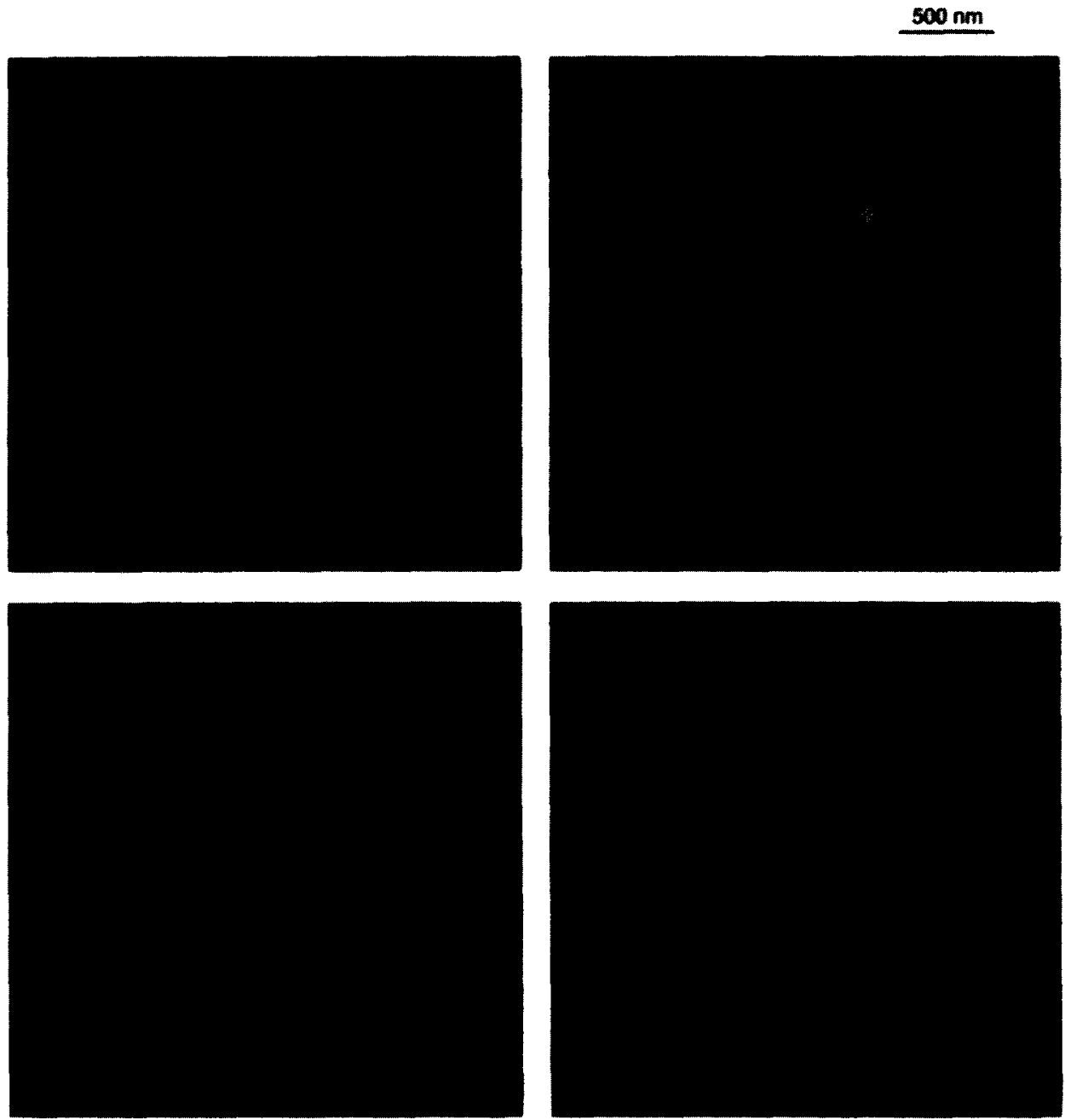

Fig. 5. Results of the analysis procedure applied to the images in Fig. $4: I_{\mathrm{k}}$-image (top left), R-image (bottom left), $\operatorname{Ln}\left(I_{\mathrm{T}} / I_{0}\right)$-image (bottom right) with grey bar from $0.0-1.0$. The structure image $(E=250 \mathrm{eV})$ is shown top right.

standard deviation of the iron loading std $-\mathrm{N}$, was studied in relation to $N_{\text {avg, }}, N_{\max }$ and $N_{\text {min }}$. The morphology of the element distribution images was visually compared to the analog electron micrographs.

\section{RESULTS}

\section{Quantification procedure}

The purpose of this section is to illustrate the acquisition and analysis procedures. Figure 3 shows an analog micrograph of the region that was analysed. In the cytoplasm of this liver parenchymal cell not only visible are very dense lysosomes and siderosomes, filled with ferritin-like particles, but also very small ferritin clusters and parts of the endoplasmatic reticulum. The microscope was set up for ESI and an image sequence is obtained according to the protocol in Table 1. Figure 4 shows a composition of the digitally acquired images. The arrangement of the images follows the ordering in Table 1. Before concentrating on the quantitative analysis, it should be investigated whether valid results may be expected from this data under the given circum- stances. First, corrections for camera distortions were performed, specimen drift was checked for and corrections carried out. Then, a ghost image was calculated from the pre-edge data set and the number of detections counted. No exceptional events were obtained. From this evaluation it was concluded that the acquisition process delivered valid data. In Fig. 5 the results of the first analysis stage are shown, together with the image acquired at $250 \mathrm{eV}$ energy-loss, which clearly depicts the morphological structure of the specimen. The image of the relative section thickness (bottom right), obtained with equation (3), shows that the values do not exceed a limit of approximately 0.6 . This means that it was justified to apply equation (2) for the quantitative analysis, of which the result is shown bottom left. Subsequently, the noise level was computed for each pixel, allowing for the SNR-image to be computed. This result is shown in Fig. 6 (bottom left). The SNR-histogram, including the detection threshold, is displayed on the top. Application of the computed threshold to the SNR-image delivers the binary result in Fig. 6, bottom right. This image shows all image locations with significant element contributions. Detected are not only the well-loaded lysosomal structures, but also a large 

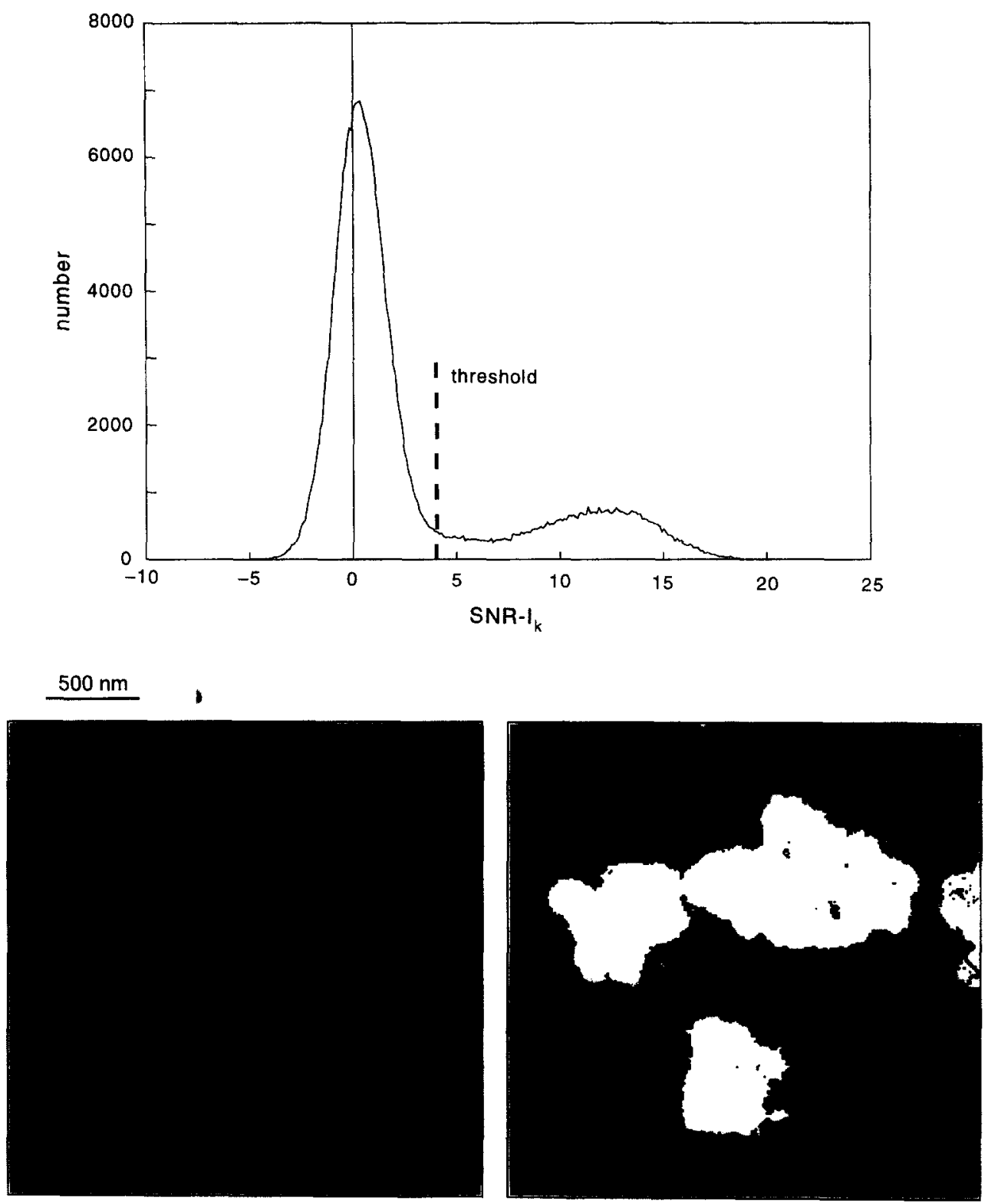

Fig. 6. The process of element detection. Histogram (top) of the signal to noise ratio image (SNR-image, bottom left). Thresholding of the SNR-image at a calculated level of 3.7 is shown (bottom right).

number of very small ferritin clusters (see also Fig. 3). For the subsequent object analysis, such small clusters were removed from the image, since structures of this size are not expected to fill the whole section and therefore distort the concentration analysis.

\section{Effect of phlebotomy}

To study the effect of phlebotomy, image acquisition and quantification were carried out according to the above described and illustrated procedures. In the five data sets of the situation A (before phlebotomy), 32 objects were detected, integrally covering an area of $5.70 \mu \mathrm{m}^{2}$. Table 2 gives an overview of the conditions and measured feature values per object. The objects are grouped per image and it is indicated which objects were calibrated with the same standard. Thus, eg., the objects A20-A25 were measured in one image and calibrated with Chelex sphere Chlx2. For situation B, 22 objects were obtained with a total area of $5.16 \mu \mathrm{m}^{2}$. The results are similarly presented in Table 3 . Both Tables 2 and 3 contain data on the concentration parameters $\left(N_{\text {avg }}\right.$, $N_{\min }$ and $N_{\max }$ ), the object inhomogeneity (std $-N$ ) and the relative section thickness, measured in each object $\left(\ln \left(I_{t} / I_{0}\right)\right.$ minimum and maximum values). The maximum values for $\ln \left(I_{t} / I_{0}\right)$ are mostly below 0.6 , which means that application of equation (2) is justified and expected to deliver valid results.

With a mean value of the average object concentration of 1.16 atoms $\mathrm{Fe} / \mathrm{nm}^{3}$ for situation $\mathrm{A}$ and 1.27 atoms/ $\mathrm{nm}^{3}$ for situation $\mathrm{B}$, the objects in the latter case seem to be slightly more heavily loaded. Since the distribution of the average object concentration was not normal for either of the situations A and B, the Wilcoxon-test was used $(a=5 \%)$ for the statistical comparison. The test revealed no significant difference in average object concentration before and after phlebotomy. 
Table 2. Overview of the measurement results in situation A (before phlebotomy)

\begin{tabular}{|c|c|c|c|c|c|c|c|c|c|}
\hline $\begin{array}{l}\text { Object } \\
\#\end{array}$ & $\begin{array}{c}\text { Standard } \\
\#\end{array}$ & $\begin{array}{l}N_{\text {avg }} \\
\text { at } / \mathrm{nm}^{3}\end{array}$ & $\begin{array}{l}N_{\min }{ }^{3} \\
\mathrm{at} / \mathrm{nm}^{3}\end{array}$ & $\begin{array}{c}N_{\max } \\
\mathrm{at} / \mathrm{nm}^{3}\end{array}$ & $\begin{array}{l}\text { std }-N \\
\mathrm{at} / \mathrm{nm}^{3}\end{array}$ & $\begin{array}{c}\ln \left(I_{t} / I_{0}\right) \\
(\mathrm{min})\end{array}$ & $\begin{array}{c}\ln \left(I_{t} / I_{0}\right) \\
(\max )\end{array}$ & $\begin{array}{c}\text { Area } \\
\text { pixels }\end{array}$ & $\mathrm{CR}$ \\
\hline $\mathrm{Al}$ & Chlxl & 1.79 & 0.35 & 2.93 & 0.44 & 0.49 & 0.72 & 17554 & 1.45 \\
\hline A2 & Chlx 1 & 1.57 & 0.38 & 3.00 & 0.46 & 0.54 & 0.73 & & \\
\hline A3 & Chlx1 & 0.92 & 0.33 & 1.76 & 0.28 & 0.49 & 0.63 & 1928 & 1.61 \\
\hline A4 & Chlx 1 & 1.27 & 0.39 & 2.56 & 0.40 & 0.55 & 0.69 & 1820 & 1.13 \\
\hline A5 & Chlxl. & 1.09 & 0.35 & 1.94 & 0.34 & 0.50 & 0.65 & 1705 & 1.43 \\
\hline A6 & Chlxl & 1.20 & 0.42 & 2.08 & 0.37 & 0.53 & 0.70 & & \\
\hline A7 & Chlx 1 & 1.55 & 0.48 & 2.55 & 0.36 & 0.50 & 0.67 & 11570 & 2.03 \\
\hline A8 & Chlx l & 1.41 & 0.48 & 2.42 & 0.32 & 0.48 & 0.65 & 6308 & 1.75 \\
\hline A9 & Chlxl & 1.09 & 0.48 & 1.87 & 0.21 & 0.49 & 0.65 & & \\
\hline $\mathrm{A} 10$ & Chlxl & 1.14 & 0.49 & 2.05 & 0.24 & 0.46 & 0.61 & 3625 & 1.85 \\
\hline All & Chlx1 & 1.11 & 0.50 & 1.83 & 0.23 & 0.46 & 0.61 & 3392 & 1.95 \\
\hline A 12 & Chlxl & 1.21 & 0.55 & 2.05 & 0.27 & 0.51 & 0.66 & 2908 & 2.30 \\
\hline A 13 & Chlxl & 1.01 & 0.49 & 1.97 & 0.19 & 0.48 & 0.64 & 2552 & 2.19 \\
\hline A14 & Chlxl & 1.35 & 0.60 & 2.14 & 0.23 & 0.52 & 0.63 & 2117 & 1.28 \\
\hline A 15 & Chlxl & 1.42 & 0.54 & 2.35 & 0.32 & 0.53 & 0.65 & & \\
\hline A16 & Chlxl & 0.90 & 0.57 & 1.37 & 0.11 & 0.52 & 0.58 & 230 & 1.44 \\
\hline A 17 & Chlx2 & 1.48 & 0.39 & 2.80 & 0.34 & 0.38 & 0.53 & 39132 & 1.91 \\
\hline A 18 & Chlx2 & 1.23 & 0.42 & 2.12 & 0.25 & 0.39 & 0.53 & 10325 & 1.61 \\
\hline A19 & Chlx2 & 0.86 & 0.48 & 1.52 & 0.14 & 0.42 & 0.53 & & \\
\hline A20 & Chlx2 & 0.89 & 0.38 & 1.78 & 0.18 & 0.40 & 0.52 & 20713 & 2.57 \\
\hline A21 & Chlx2 & 1.04 & 0.37 & 1.84 & 0.22 & 0.41 & 0.54 & & \\
\hline A 22 & Chlx2 & 1.19 & 0.39 & 2.11 & 0.27 & 0.42 & 0.52 & 5059 & 1.26 \\
\hline A23 & Chlx2 & 1.13 & 0.38 & 1.98 & 0.25 & 0.39 & 0.51 & & \\
\hline A24 & Chlx2 & 1.06 & 0.40 & 1.83 & 0.28 & 0.40 & 0.49 & 577 & 1.48 \\
\hline A 25 & Chlx2 & 0.93 & 0.41 & 1.65 & 0.27 & 0.40 & 0.49 & 374 & 1.37 \\
\hline A26 & Chlx2 & 1.16 & 0.38 & 2.08 & 0.24 & 0.41 & 0.53 & 15292 & 1.62 \\
\hline A27 & Chlx2 & 1.08 & 0.41 & 1.84 & 0.23 & 0.42 & 0.57 & & \\
\hline A28 & Chlx2 & 1.03 & 0.40 & 2.03 & 0.29 & 0.41 & 0.53 & 3036 & 1.94 \\
\hline A 29 & Chlx2 & 1.10 & 0.40 & 1.88 & 0.26 & 0.43 & 0.55 & & \\
\hline A 30 & Chlx2 & 0.85 & 0.41 & 1.48 & 0.13 & 0.43 & 0.52 & 1319 & 1.52 \\
\hline A31 & Chlx2 & 0.99 & 0.42 & 1.64 & 0.25 & 0.40 & 0.53 & 859 & 1.39 \\
\hline A32 & Chlx2 & 0.92 & 0.45 & 1.44 & 0.15 & 0.46 & 0.54 & & \\
\hline
\end{tabular}

Table 3. Overview of the measurement results after phlebotomy (situation B)

\begin{tabular}{|c|c|c|c|c|c|c|c|c|c|}
\hline $\begin{array}{l}\text { Object } \\
\#\end{array}$ & $\underset{\#}{\text { Standard }}$ & $\begin{array}{r}N_{\text {avg }_{3}} \\
\text { at } / \mathrm{nm}^{3}\end{array}$ & $\begin{array}{c}N_{\min } \\
\mathrm{at} / \mathrm{nm}^{3}\end{array}$ & $\begin{array}{l}N_{\max } \\
\mathrm{at} / \mathrm{nm}^{3}\end{array}$ & $\begin{array}{l}\text { std }-N \\
\text { at } / \mathrm{nm}^{3}\end{array}$ & $\begin{array}{c}\ln \left(I_{t} / I_{0}\right) \\
(\mathrm{min})\end{array}$ & $\begin{array}{c}\ln \left(I_{t} / I_{0}\right) \\
(\max )\end{array}$ & $\begin{array}{c}\text { Area } \\
\text { pixels }\end{array}$ & CR \\
\hline $\begin{array}{l}\text { B1 } \\
\text { B2 }\end{array}$ & $\begin{array}{l}\text { Chlx3 } \\
\text { Chlx3 }\end{array}$ & $\begin{array}{l}1.48 \\
1.15\end{array}$ & $\begin{array}{l}0.36 \\
0.37\end{array}$ & $\begin{array}{l}2.84 \\
2.12\end{array}$ & $\begin{array}{l}0.51 \\
0.36\end{array}$ & $\begin{array}{l}0.32 \\
0.33\end{array}$ & $\begin{array}{l}0.48 \\
0.46\end{array}$ & $\begin{array}{c}10802 \\
7489\end{array}$ & $\begin{array}{l}1.50 \\
1.53\end{array}$ \\
\hline $\begin{array}{l}\text { B3 } \\
\text { B4 } \\
\text { B5 } \\
\text { B6 } \\
\text { B7 } \\
\text { B8 }\end{array}$ & $\begin{array}{l}\text { Chlx3 } \\
\text { Chlx3 } \\
\text { Chlx3 } \\
\text { Chlx3 } \\
\text { Chlx3 } \\
\text { Chlx3 }\end{array}$ & $\begin{array}{l}1.27 \\
1.51 \\
1.45 \\
1.17 \\
1.34 \\
0.75\end{array}$ & $\begin{array}{l}0.42 \\
0.41 \\
0.36 \\
0.39 \\
0.44 \\
0.37\end{array}$ & $\begin{array}{l}2.93 \\
3.47 \\
2.27 \\
2.51 \\
2.02 \\
1.33\end{array}$ & $\begin{array}{l}0.43 \\
0.57 \\
0.35 \\
0.46 \\
0.32 \\
0.17\end{array}$ & $\begin{array}{l}0.29 \\
0.29 \\
0.29 \\
0.31 \\
0.31 \\
0.28\end{array}$ & $\begin{array}{l}0.51 \\
0.50 \\
0.43 \\
0.49 \\
0.44 \\
0.37\end{array}$ & $\begin{array}{l}9248 \\
4814 \\
4084 \\
3224 \\
2850 \\
1995\end{array}$ & $\begin{array}{l}1.23 \\
1.24 \\
1.41 \\
2.21 \\
1.20 \\
2.54\end{array}$ \\
\hline $\begin{array}{l}\text { B9 } \\
\text { B10 }\end{array}$ & $\begin{array}{l}\text { Chlx3 } \\
\text { Chlx3 }\end{array}$ & $\begin{array}{l}1.22 \\
1.52\end{array}$ & $\begin{array}{l}0.35 \\
0.41\end{array}$ & $\begin{array}{l}2.61 \\
2.70\end{array}$ & $\begin{array}{l}0.48 \\
0.51\end{array}$ & $\begin{array}{l}0.32 \\
0.36\end{array}$ & $\begin{array}{l}0.52 \\
0.55\end{array}$ & $\begin{array}{l}5534 \\
3730\end{array}$ & $\begin{array}{l}1.98 \\
1.54\end{array}$ \\
\hline $\begin{array}{l}\text { B11 } \\
\text { B12 } \\
\text { B13 } \\
\text { B14 } \\
\text { B15 }\end{array}$ & $\begin{array}{l}\text { Chlx3 } \\
\text { Chlx3 } \\
\text { Chlx3 } \\
\text { Chlx3 } \\
\text { Chlx3 }\end{array}$ & $\begin{array}{l}1.44 \\
1.59 \\
0.99 \\
0.81 \\
0.71\end{array}$ & $\begin{array}{l}0.40 \\
0.44 \\
0.47 \\
0.44 \\
0.45\end{array}$ & $\begin{array}{l}3.28 \\
2.59 \\
1.67 \\
1.21 \\
1.16\end{array}$ & $\begin{array}{l}0.51 \\
0.38 \\
0.22 \\
0.13 \\
0.12\end{array}$ & $\begin{array}{l}0.28 \\
0.28 \\
0.33 \\
0.32 \\
0.31\end{array}$ & $\begin{array}{l}0.48 \\
0.49 \\
0.42 \\
0.39 \\
0.38\end{array}$ & $\begin{array}{c}23644 \\
6562 \\
311 \\
295 \\
171\end{array}$ & $\begin{array}{l}2.50 \\
1.24 \\
1.14 \\
1.55 \\
1.39\end{array}$ \\
\hline $\begin{array}{l}\text { B16 } \\
\text { B17 }\end{array}$ & $\begin{array}{l}\text { Chlx4 } \\
\text { Chlx4 }\end{array}$ & $\begin{array}{l}2.18 \\
2.41\end{array}$ & $\begin{array}{l}0.52 \\
0.47\end{array}$ & $\begin{array}{l}3.94 \\
4.71\end{array}$ & $\begin{array}{l}0.68 \\
0.96\end{array}$ & $\begin{array}{l}0.31 \\
0.26\end{array}$ & $\begin{array}{l}0.51 \\
0.55\end{array}$ & $\begin{array}{l}23136 \\
9729\end{array}$ & $\begin{array}{l}1.36 \\
1.88\end{array}$ \\
\hline $\begin{array}{l}\text { B18 } \\
\text { B19 }\end{array}$ & $\begin{array}{l}\text { Chlx4 } \\
\text { Chlx4 }\end{array}$ & $\begin{array}{l}1.27 \\
0.71\end{array}$ & $\begin{array}{l}0.39 \\
0.40\end{array}$ & $\begin{array}{l}2.70 \\
1.17\end{array}$ & $\begin{array}{l}0.37 \\
0.07\end{array}$ & $\begin{array}{l}0.34 \\
0.37\end{array}$ & $\begin{array}{l}0.55 \\
0.45\end{array}$ & $\begin{array}{c}23563 \\
708\end{array}$ & $\begin{array}{l}3.21 \\
2.22\end{array}$ \\
\hline $\begin{array}{l}\text { B20 } \\
\text { B21 } \\
\text { B22 }\end{array}$ & $\begin{array}{l}\text { Chlx4 } \\
\text { Chlx4 } \\
\text { Chlx4 }\end{array}$ & $\begin{array}{l}1.00 \\
0.96 \\
0.99\end{array}$ & $\begin{array}{l}0.40 \\
0.43 \\
0.41\end{array}$ & $\begin{array}{l}2.33 \\
1.61 \\
1.53\end{array}$ & $\begin{array}{l}0.27 \\
0.15 \\
0.20\end{array}$ & $\begin{array}{l}0.32 \\
0.39 \\
0.37\end{array}$ & $\begin{array}{l}0.55 \\
0.50 \\
0.46\end{array}$ & $\begin{array}{c}25332 \\
2422 \\
838\end{array}$ & $\begin{array}{l}2.89 \\
1.46 \\
1.31\end{array}$ \\
\hline
\end{tabular}

\section{Particle morphology}

The quantitative results of the analysis of the morphology by area measurement and contour-ratio measurement are also collected in Table 2 for situation
A and in Table 3 for situation $B$. The missing values for each of the situations are caused by the fact that objects touching the image border were not measured. To investigate the relation between the average object loading and its shape, scatter plots of the area versus $N_{\text {avg }}$ 
(a)

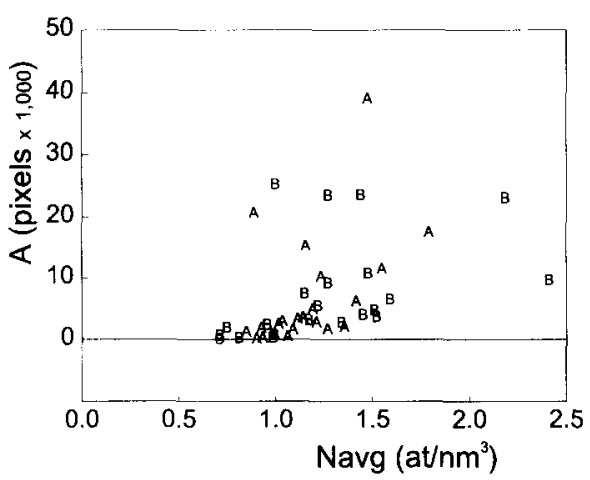

(b)

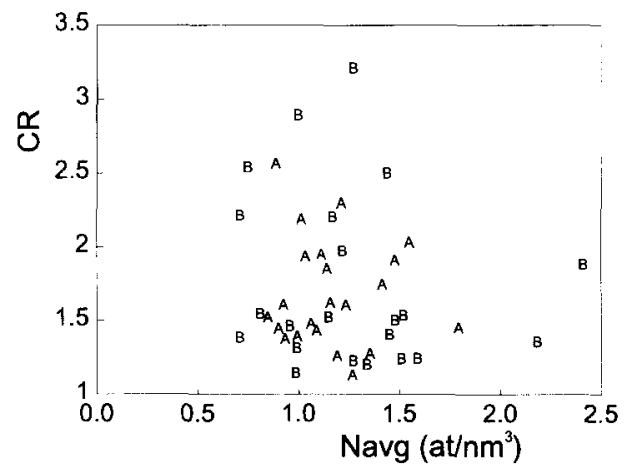

(c)

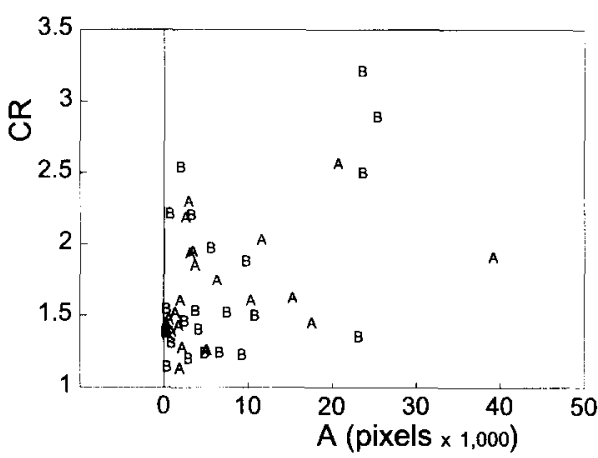

Fig. 7. Scatter plots for analysis of the shape of iron containing structures, before and after phlebotomy: (a) area (A) versus $N_{\text {avg }}$, (b) contour ratio (CR) versus $N_{\text {avg, }}$, (c) contour ratio (CR) versus area $(\mathrm{A})$.

and of CR versus $N_{\text {avg }}$ were made, as shown in Fig. $7 \mathrm{a}$ and $b$, respectively. Figure $7 c$ shows the relationship between the shape parameters. There is no marked structure visible in these figures for either of the cases A and $\mathrm{B}$. Also, no differences are present between the situation before and after phlebotomy.

The inhomogeneity of the individual objects was analysed by measuring the standard deviation $(\mathrm{std}-\mathrm{N})$ of the iron concentration. The relationships between std - $\mathrm{N}$ on one hand and $N_{\text {avg }}, N_{\min }$ and $N_{\max }$ on the other hand are shown in Fig. 8. The linear regression lines are also drawn for each of the parameters and for each of the cases A and B. Before and after phlebotomy there is a very similar and apparent linear relationship between object inhomogeneity and loading $\left(N_{\text {avg }}\right.$ and $N_{\text {max }}$ ). The data for $N_{\min }$ shows a horizontal behaviour.

Std $-N$ and both morphological parameters were also plotted, but as can be understood from Fig. 8 these representations did not yield any new information and are therefore not shown.
For a qualitative treatment of morphology, the iron distribution images were compared with the more conventional (energy-filtered) analog electron micrographs. Figure 3 shows an example of such a micrograph of the patient tissue before phlebotomy treatment. Dense regions can be observed, which are visually suggested to contain more iron. The iron measurements in Fig. 5, however, could not associate a higher iron content to these regions. The difference in morphology between iron map and micrograph stresses that the interpretation of the micrographs at this point cannot be performed without the production of iron proportional images.

\section{DISCUSSION}

\section{Quantification procedure}

The quantitative procedures for the measurement of iron were demonstrated and illustrated with material that was used for the analysis of a pathological overload condition of the human liver. All guideline aspects that were formulated in the beginning of this paper have been carefully considered. As a result of the procedure it was shown that even very small clusters of ferritin could be detected in patient material.

\section{Effect of phlebotomy}

No difference could be measured in average object concentration between the situations before and after phlebotomy. The iron that was removed from the liver was most probably not removed from the structures such as analyzed in situation B. It may even be presumed that the cells in which these structures lie, have not yet answered to the demand of iron. It must be noted that the measurements were performed in parenchymal cells, of which the location within the liver was undetermined. The selection of locations was triggered by the visual presence of electron dense structures, such as clusters, lysosomes or siderosomes. Because light-microscopical observations of histological sections revealed a lower grade of iron-loading of the liver after phlebotomy, but no difference between the concentration in the two situations could be measured, this experiment supports the hypothesis that iron containing structures are catabolized one by one. This is similar to the way ferritin is catabolized (Mostert et al., 1989). The result is not in agreement with the measurements performed by Cleton et al. $(1986,1988)$. The reason for this may be caused by the histologically insufficiently well-determined measurement locations. Because of the discrepancy, it is now believed that the location of the parenchymal cells relative to the descendant of the portal vein should be specified and that an equal number of object types (cluster, lysosome, siderosome) before and after phlebotomy should be addressed. Furthermore it should be realized that the quantitative results in this study are expressed in atoms per unit volume, while Cleton et al. 


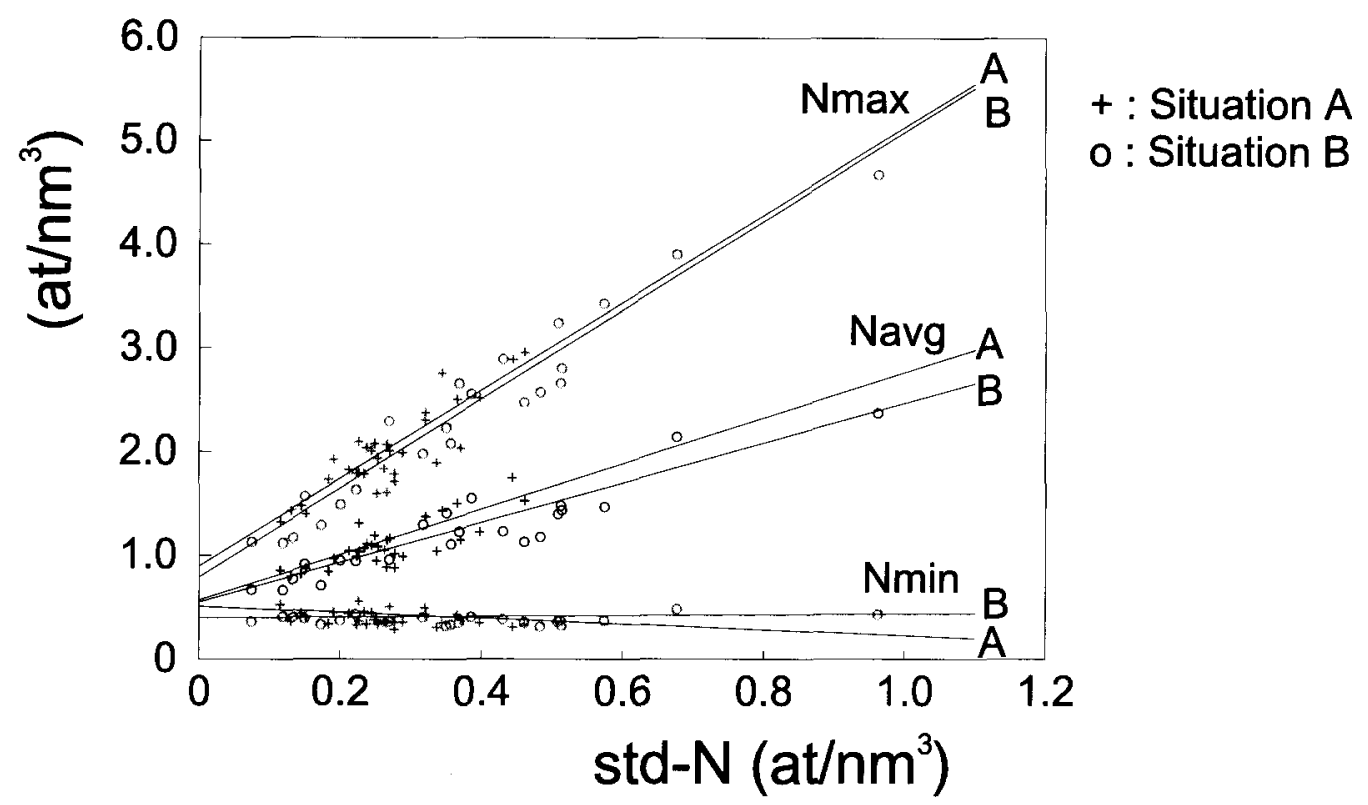

Fig. 8. Scatter plots of the relationships between object inhomogeneity (std $-N$ ) and the concentration parameters $N$ min, $N$ avg and $N \max$ for the situations before (A) and after (B) phlebotomy.

(1986) expressed the quantities as weight percentages. Volume effects influence the former quantities, while mass effects influence the latter.

\section{Particle morphology}

The purpose of the morphological analysis was twofold: to see whether simple parameters such as $A$ and CR contribute to the type discrimination and to see whether phlebotomy has had any effect on the morphology. Figure 7 a only vaguely contains some structure, but the question is whether this is artificial or not. The area of an object naturally depends on the way it was sectioned and, as a result, a large 3-D object may be seen as a small one in certain 2-D cross-sections. In Fig. $7 \mathrm{~b}$, no structure is visible at all. The conclusion of these measurements is that there is no marked difference between the situations A and B. Also, no clear indication could be obtained about the usefulness of the described morphologic parameters for the typing of the objects.

Figure 8 indicates that the average concentration and the maximum concentration of an object and the standard deviation of the concentration distribution of the object correlate well. The visual impression that the inhomogeneity increases with the average object loading is hereby confirmed. The horizontal behaviour of the measured minimum concentration is not surprising if we think of $N_{\min }$ as the detection limit. The radiation intensity and related to that the quantum noise determines the minimally detectable quantities of the element. Since virtually equal microscope beam intensity settings were used for acquisition of the various image sets, approximately equal detection limits may be expected in the results.

Considering the morphology qualitatively, it can be concluded that the use of the electron micrograph density as an indication for the presence of iron is questionable. Reversely, subregions with high iron concentrations are found, which do correlate well with the presence of dense subregions. Because these subregions are of the compact type, it seems logical to conclude that either these regions originate from a biochemical process with a limited extent, or that they are the final result of such a process elsewhere and that these structures have been incorporated in a later stage. In Beckers et al. (1996) it was demonstrated that the iron structures can be characterized in greater detail by further analysis of the iron distribution of the individual objects.

\section{REFERENCES}

Beckers, A. L. D., Gelsema, E. S. and de Bruijn, W. C., 1993. An efficient method for calculating the least squares background fit in electron energy-loss spectroscopy. J. Microsc., 171, 87-92.

Beckers, A. L. D., de Bruijn, W. C., Gelsema, E. S., Cleton-Soeteman, M. I. and van Eijk, H. G., 1994. Quantitative electron spectroscopic imaging in bio-medicine: methods for imageacquisition, correction and analysis. J. Microsc., 174, 171-182.

Beckers, A. L. D., Gelsema, E. S., de Bruijn, W. C., Cleton-Soeteman, M. I. and van Eijk, H. G., 1996. Quantitative electron spectroscopic imaging in bio-medicine: Evaluation and application. J. Microsc., 183, 78-88.

Bonnet, N., Colliex, C., Mory, C. and Tence, M., 1988. Developments in processing image sequences for elemental mapping. Scan. Microsc. Suppl., 2, 351-364.

De Bruijn, W. C. and Cleton-Soeteman, M. I., 1985. Application of Chelex standard beads integrated morphometrical and X-ray microanalysis. Scan. Electr. Microsc., II, 715-729.

De Bruijn, W. C., Sorber, C. W. J., Gelsema, E. S., Beckers, A. L. D. and Jongkind, J. F., 1993. Energy-filtering transmission electron microscopy of biological specimens. Scan. Electr. Microsc., 7, 693-709.

Cleton, M. I., Roelofs, J. M., Blok-Van Hoek, C. J. G. and de Bruijn, W. C., 1986. Integrated image and X-ray microanalysis of hepatic lysosomes in idiopathic hemochromatosis before and after treatment by phlebotomy. Scan. Electr. Microsc, 3, 999-1006.

Cleton, M. I., de Bruijn, W. C., Blokland, W. T. M., Marx, J. J. M., Roelofs, J. M. and Rademakers, L. H. P. M., 1988. Iron content and acid phosphatase activity in hepatic parenchymal lysosomes of patients with heamochromatosis before and after phlebotomy treatment. Ultrastruct. Pathol., 12, 161-174. 
Colliex, C., 1985. An illustrated review of various factors governing the high spatial resolution capabilities in EELS microanalysis. Ultramicroscopy, 18, 131-150.

Colliex, C., Manoubi, T. and Krivanek, O. L., 1986. EELS in the electron microscope: A review of present trends. J. Electr. Microsc., 35, 307-313.

Egerton, R. F., 1986. Electron Energy-Loss Spectroscopy in the Electron Microscope, pp. 193-195, 264-266, Plenum Press, New York.

Egerton, R. F. and Cheng, S. C.. 1987. Measurement of local thickness by electron energy-loss spectrometry. Ultramicroscopy, 21, 231-244.

Mostert, L., Cleton, M. I., De Bruijn, W. C., Koster, J. F. and van Eijk, H. G., 1989. Studies on ferritin in rat liver and spleen during repeated phlebotomy. Int. J. Biochem., 21, 39-47.

Reimer, L., 1991. Energy filtering transmission electron microscopy. In Advances in electronics and electron physics, Vol. 81, pp. 43-126. Academic Press Inc., New York.

Scheuer, P. J., 1977. Liver biopsy interpretation, 2nd edn. Bailiere, Tindall and Cassel, London.
Sorber, C. W. J., de Jong, A. A. W., den Breejen, N. J. and de Bruijn, W. C., 1990. Quantitative energy-filtered image analysis in cytochemistry, I. Morphometric analysis of contrast-related images. Ultramicroscopy, 32, 55-68.

Sorber, C. W. J., Ketelaars, G. A. M., Gelsema, E. S., Jongkind, J. F. and de Bruijn, W. C., 1991. Quantitative analysis of electron energy-loss spectra from ultrathin-sectioned biological material. II. The application of Bio-standards for quantitative analysis. J. Microsc., 162, 43-54.

Stearns, R. C., Marshall, K. and Godleski, J. J., 1994. Contribution of osmium tetroxide to the image quality and detectability of iron in cells studied by electron spectroscopic imaging and electron energy-loss spectroscopy. Microsc. Res. Tech. 28, 155-163.

Unser, M., Ellis, J. R., Pun, T. and Eden, M., 1987. Optimal background estimation in EELS. J. Microsc., 145, 245 256.

Van Puymbroeck, J., Jacob, W. and van Espen, P., 1992. Methodology for spectrum evaluation in quantitative electron energy-loss spectrometry using the Zeiss CEM 902. J. Microsc., 166, 273-286. 